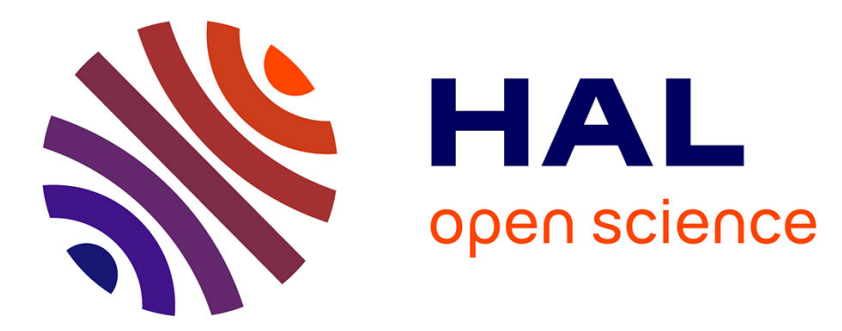

\title{
The Perceived Effectiveness of Interactions Between Expert French Judo Coaches and Elite Female Athletes
}

Fabienne d'Arripe-Longueville, Jean F. Fournier, Alice Dubois

\section{To cite this version:}

Fabienne d'Arripe-Longueville, Jean F. Fournier, Alice Dubois. The Perceived Effectiveness of Interactions Between Expert French Judo Coaches and Elite Female Athletes. Sport Psychologist, 1998, 12 (3), pp.317-332. 10.1123/tsp.12.3.317 . hal-01712645

\section{HAL Id: hal-01712645 \\ https://hal-insep.archives-ouvertes.fr/hal-01712645}

Submitted on 20 Feb 2018

HAL is a multi-disciplinary open access archive for the deposit and dissemination of scientific research documents, whether they are published or not. The documents may come from teaching and research institutions in France or abroad, or from public or private research centers.
L'archive ouverte pluridisciplinaire HAL, est destinée au dépôt et à la diffusion de documents scientifiques de niveau recherche, publiés ou non, émanant des établissements d'enseignement et de recherche français ou étrangers, des laboratoires publics ou privés. 


\title{
The Perceived Effectiveness of Interactions Between Expert French Judo Coaches and Elite Female Athletes
}

\author{
Fabienne d'Arripe-Longueville, Jean F.Fournier, \\ and Alice Dubois \\ Institut National du Sport et de l'Education Physique
}

\begin{abstract}
Coaches' and athletes' perceptions regarding their effective interactions and the underlying factors and reasons for effectiveness of these interactions were examined. An in-depth interview process was conducted with three expert judo coaches and six elite athletes. Qualitative data analyses revealed that the interaction style of the coaches was authoritative and was put into operation using the following six strategies: stimulating interpersonal rivalry, provoking athletes verbally, displaying indifference, entering into direct conflict, developing specific team cohesion, and showing preferences. Perceived autonomy, the main interaction style of athletes, was expressed by the following five strategies: showing diplomacy, achieving exceptional performance, soliciting coaches directly, diversifying information sources, and bypassing conventional rules. Results demonstrated the compatibility of particular interactions between coaches' and athletes' strategies. Theoretical models from industrial/organizational psychology are nsed to interpret these results, which differ from conventional findings in the sport psychology literature.
\end{abstract}

Judo is a source of national pride for French citizens. The political infrastructure of the goveming body for the federal sport as well as that of coaches and athletes are derived from the country's strong tradition of excellence in this sport France's recent international results injudo include seven medals at the 1992 Olympie Games, six at the 1996 Olympics, and nine at the 1997 World Judo Championships. Mechanisms of this productive system are worth investigating and have not yet generated any studies. Because the coach is always present on the mat during judo training and competition, coach-athlete interactions are prominent and are deemed a relevant component of this productive French system.

Fabienne d'Arripe-Longueville, Jean Fournier, and Alice Dubois are with the Laboratoire de Psychologie Appliquée au Sport at the Institut National du Sport et de !'Education Physique, 11Avenue du Tremblay, 75012, Paris, France. 
In recent years, studies on coach-athlete relationships have mainly been conducted within the framework of the multidimensional model of leadership (Chelladurai \& Carron, 1978). According to this model, athletes' performance and satisfaction depend primarily on the degree of congruence among the coach's actuai behavior, the coach's behavior preferred by athletes, and the behaviorrequired by the situation. The Leadership Scale for Sport (LSS), adapted from managers' behaviors, is composed of five leadership styles (Chelladurai \& Saleh, 1980): training and instruction, democratic behavior, autocratie behavior, social support, and positive feedback. This model has generated many studies in different sports and cultural contexts (Chelladurai, 1993). One of the interests of this approach lies in the fact that athletes' coaching preferences (Terry \& Howe, 1984) and compatibility in coach-athlete relationships (Horne \& Cimon, 1985) can be further investigated. However, this model was designed neither to analyze how and why coaches and athletes internet in complex athletic settings nor to investigate the dynamic process underlying effectiveness in specific situations.

More recently, researchers have focused on coaching expertise, using indepth interviews and qualitative data analysis. Using this inductive approach with high-performance gymnastic coaches, Côté and colleagues (Côté, Salmela, Trudel, Baria, \& Russell, 1995) devised a model of athletes' development process. This model included three central coaching variables in training, competition, and organizational components, which related to coaches' behaviors. Coaches' and athletes' persona! characteristics, athletes' development levels, contextual factors, and training goals were identified as affecting the aforementioned variables. The knowledge and strategies used by coaches in competition and training (Côté, Salmela, \& Russell, 1995) and in organizational settings have also been studied (Côté \& Salmela, 1996).

Côté, Salmela, and Russell (1995) identified coaches' involvement in training, intervention style, technical skills, mental skills, and simulation as important components. Intervention style was specifically characterized by giving athletes responsibilities, being supportive, gaining respect from gymnasts, asking for quality training, and keeping an appropriate persona! distance. In Côté and Salmela's (1996) study, analysis indicated that expert gymnastic coaches were constantly involved in dynamic social interactions with gymnasts, parents, and assistant coaches. Handling athletes' persona! concerns and working with parents emerged as crucial tasks for expert gymnastic coaches.

Using a similar methodology, Saury and Durand (1995) focused on the coachathlete relationships among members of the French Olympie sailing team. These relationships were defined as cooperative activities, including collective goals. They outlined the following four coaches' strategies: adopting an empathetic attitude toward athletes, tactful negotiation during training, defining a margin of autonomy for athletes during training, and using a "communal reference point" regarding shared knowledge and experiences. Such studies have helped to develop a holistic and comprehensive outline based on coaches' cognitions and perceptions. However, these qualitative studies on coaching expertise have only involved investigating coaches' perceptions. Athletes' viewpoints, which have been overlooked, are seemingly crucial to characterize the effectiveness of their interactions with coaches.

In the present study, we attempted to expand the preexisting literature on coaching expertise by examining coaches' and athletes' perceptions regarding their effective interactions, the underlying factors of these interactions, and the reasons 
for effectiveness. Côté et al.'s ( 1995) coaching model provided theoretical support for this study. First, we used in-depth interviews to explore coaches' and athletes' behaviors and strategies in training and competition settings. Secondly, underlying factors were analyzed in regard to the three dimensions of the coaching model: coach's persona characteristics, athlete's personal characteristics, and contextual factors. In addition, the perceived reasons for the effectiveness of coaches' and athletes' interactions were explored through interviews. These dimensions were not directly investigated in previous research on coaching expertise. It was hypothesized that involving and comparing coaches' and athletes' arguments would help characterize the dynamic process of the perceived effectiveness of these interactions. A qualitative methodology loosely based on Strauss and Corbin's (1990) theory was used to identify and categorize these behaviors, strategies, underlying factors, and perceived reasons for effectiveness.

\section{Method}

\section{Participants}

Three male coaches and six female athletes from the French national judo team volunteered to participate in the study. Coaches satisfied Côté, Salmela, and Russell's ( 1995a, 1995b) criteria of expert coaches. Coaches were directly responsible for overseeing the French national judo female team's Olympie preparation. All six athletes had international titles and had been selected for the 1996 Olympie team. These criteria ensured that participants were (and still are) among the best coaches and athletes in the world. To guarantee anonymity, a coding system was used to attribute quotations. A letter identified the participant as coach (C) or athlete (A).

\section{Interview Guide}

Relative training and competition themes were drawn from Orlick's (1986) athlete interview guides and from otherjudo-related issues that emerged from a pilot study conducted with junior team coaches and athletes from various sports. The same guide was used with coaches and athletes, and questions were formulated to probe training and competition situations that coaches and athletes deemed significant. However, other topics that where relevant to study objectives were also investigated.

Five types of questions were used in the interviews, with the first three categories having been proposed by Spradley (1979). The first category contained descriptive questions, which helped identify important situations of the participant (e.g., a good performance, a bad training session). The second category included structural questions, which generated precise information on a given situation and outlined the underlying factors (e.g., questions regarding details, such as where, with whom, and expressed in what manner). Thirdly, contrast questions required the participant to examine the situation from an opposing perspective (e.g., with very young or old athletes). The fourth category consisted of justification questions, which probed coaches' and athletes' perceived reasons for this effectiveness regarding their interactions (e.g., "Ifyou were to re-live a certain experience, would you do it differently?" or "What makes this behavior effective?" or "How can you explain it?"). The last category consisted of confirmable questions, which corroborated mentioned behaviors, strategies, or arguments (e.g., phrasing a question 
in a contradictory manner). In addition, this last category enabled researchers to obtain participants' agreement on their responses.

\section{Interview Format}

The in-depth interviews were each a minimum of $2 \mathrm{hr}$. Each interview began with a presentation of the study objectives. The study was presented as an investigation of respective high-level experience, knowledge, and styles of the participants' coaching or training. Because of the delicate nature of coach-athlete interactions within the French judo system, we supposed that direct questions focusing on participants' interactions would inhibit their authenticity. Moreover, we hypothesized that investigating behaviors and strategies in varions training or competitive situations would help to develop a comprehensive outline of coach-athlete interactions, including all process variables. Permission to record and transcribe the interviews verbatim was obtained from each participant.

Two researchers participated in each interview according to a procedure based on immediate inductive analysis, borrowed from Scanlan (1993). One researcher conducted the interview, while the second researcher identified and recorded salient behaviors, strategies, underlying factors, and reasons for effectiveness that were related to the study objectives. The second researcher wrote a code for each element on removable self-stick notes. The participant could then comment on these notes. At the end of each interview, they were displayed on a dry-erase board. During the interview, arrows and boxes were drawn with an erasable marker to regroup behaviors, strategies, underlying factors, or perceived reasons for effectiveness. Researchers or the participant suggested the name of each main category according to common features of the elements. Links between the categories were also specified. This cooperative process contributed to a participant' s profile, which was considered complete when the participant had indicated satisfaction. Participants were told that the profile could be further modified by contacting either interviewer before or after receiving the verbatim transcript.

\section{Data Anal ysis}

Three researchers were involved in the complete data analysis. One had previous experience in qualitative research methods. The other two received intensive methodological guidance from the experienced investigator and had read relevant literature about interviewing techniques and qualitative methods. Two of these researchers had considerable competitive judo experience.

Data were analyzed in three stages. First, each interview was transcribed verbatim. Situations, generalizations, and perceived reasons for effectiveness relating to coach-athlete interactions that were deemed significant were selected independently by each researcher. Inthe second stage, we examined the coding using procedures and inductive categorization methods inspired by grounded theory principles (Strauss \& Corbin, 1990). However, all canons and procedures were not followed (e.g., theoretical memos were not systematically used after each interview, such as when an emerging theme was discussed and subsequently probed in following interviews). Agreement was reached concerning significant text excerpts, number and designation of subcategories, and links between categories after independent coding. During this stage, resea:rchers went back to each profile to refine their inductive analyses, but essentially the categories did not change further. 
However, in a few cases, profiles obtained in the interviews influenced later analyses for links between categories.

The third and final stage was used to select the same situations described by coaches and athletes to analyze their respective behaviors and strategies. Effectiveness of interactions was defined by the congruence between respective strategies and adequacy concerning the given situational constraints. No new salient themes emerged after analyzing the interview with the second coach and that with the fifth athlete, indicating that theoretical saturation was reached (Glaser \& Strauss, 1967).

\section{Assuring Credibility}

Severa! measures were taken to establish data credibility. First, at the end of the interview process or within the 2 months following, profiles were approved by all participants. Secondly, transcribed interviews were returned to participants to ensure the authenticity of their commentary and to allow them to make changes to the text. Minor editorial comments were made. Four participants wanted to be more explicit in their statements, while others did not change the text.

\section{Results}

The emerging categories regarding interaction strategies and underlying factors were different for athletes and coaches, whereas some perceived reasons for effectiveness were shared. Each coach was represented in each interaction strategy as were all athletes in their respective interaction strategies. All of the coaches' strategies were described by coaches and athletes, whereas those of athletes were elicited by only two coaches. However, the frequency of category representation was not deemed relevant to defining the effectiveness of coaches' and athletes' interactions. A quantitative criterion did not contribute to determining the adequacy of respective strategies to situational constraints. In this way, effectiveness emerged from coordinating coaches' and athletes' respective strategies in regard to common situatîons and goals.

Results are presented in three sections. The first two include coaches' and athletes' specific analyses of strategies. The third provides an overview of their compatibility and effectîveness in common situations. Quotations have been translated by two bilingual researchers.

\section{Coaches' Interaction Strategies}

Table 1 lists the categories and characteristics that emerged from analyses of coaches' interview transcripts regardîng effective interactions with athletes, underlying factors of these interactions, and the reasons for their effectiveness.

The dominant interaction style adopted by expert judo coaches was authoritarian and was manifested by exerting control over athletes, unilateral decision making, maintaining a continuons presence in training and competition, establishing a disciplined rigid climate, and using negative feedback. Six specific interaction strategies emerged within this autocratie coaching style. They were occasionally exhibited independently but were more frequently combined with one or more strategies. Coaches' strategies were represented by stimulating interpersonal rivalry between athletes, provoking athletes verbally, displaying indifference, entering into direct conflict, developing team cohesion, and exhibîting favoritism. 
Table J Categories and Characteristics of Coaches' Interaction Strategies

$\begin{array}{lll}\begin{array}{l}\text { Coaches' interaction } \\ \text { strategies }\end{array} & \begin{array}{l}\text { Underlying interaction } \\ \text { factors }\end{array} & \begin{array}{l}\text { Perceived reasons for } \\ \text { effective interactions }\end{array}\end{array}$

Stimulating interpersonal rivalry: social comparison and unfair selection processes

Provoking athletes
verbally: aggressive,
ironie toues and
negative feedback
Displaying indifference:
intentional lack of
interest in athletes and
complete lack of
communication

Entering into direct conflict: lack of interest and communication and threats regarding selection

Developing specific team cohesion: facing challenging situations

Exhibiting favoritism: increased instructions and feedback and increased tolerance
Political issues in the French Judo Federation: international results and coaches' conception of elitism

Coaches' perception of athletes' personalilies: need for provocation

Judo culture: coaches' experience in the system, respect and distance in coach-athlete relationship, and perpetual efforts

Coaches' perception of athletes' personalities: expectations about athletes' efforts and adaptation

Coaches' perceptions of athletes' potential: bets on athletes
Mental preparation: positive consequences on athletes' motivation

Technical, tactical, and mental preparation: positive consequences on athletes' commitment

Mental testing: pushing athletes to keep the most resilient

Mental testing: pushing athletes and waiting for their adaptation

Mental preparation: development of a "winning" spirit and intimidation of opponents

Stimulating lnterpersonal Rivalry Between Athletes. Thisparticular strategy manifested itself in encouraging social comparison during training and adopting unfair selection processes. The following quotation illustrates these elements:

They don't like each other much; they are rivals. There is a group feeling and they fight like cats and dogs. It is fantastic and it is how you advance and progress. (C2)

This strategy is highly related to the politics of French judo and coaches' conceptions of elitism. The positive consequences of rivalry to create a competitive climate and increase athletes' motivation are seen as reasons to adopt such a strategy, as expressed by this coach: 
For them to advance toward the goal of becoming the best senior athlete, they are never going to be permitted to get comfortable on the throne (at the top).... They are constantly obliged to advance. ... The best in a given category is never in a stable position. It is a means of motivation. If the number 1 athlete says to herself, " My butt is on fire," she will continue to stay in front. It's like running when you feel someone's breath on your back: You speed up. (C3)

Provoking Athletes Verbally. Provoking athletes was a second strategy adopted by judo coaches, as seen in use of aggressive or ironie tones during verbal exchanges, or negative feedback in training or just before competition. Ali of the coaches perceived these strategies as essential to developing each athlete's technical, tactical, and mental aspects. Provocation was also seen as a positive stimulant in terms of optimizing performance. The following demonstrates one coach's provocative strategies before a competition:

There are rimes when you must shock them, provoke them, so that they work their butts off. You have to be aggressive, especially with those athletes who doubt themselves or think too much before a competition. $(\mathrm{Cl})$

Coaches' perceptions of athletes' personalities emerged as an important underlying factor, as stated by this coach:

This is a girl, you know, who has ups and downs, which means that it isn't obvious how to lead her. To tell the truth, several rimes I've deliberately provoked her, because I know her. You have to provoke her. (C2)

Displaying Indifference to Athletes. Displaying indifference was another strategy frequently used by French judo coaches, as seen in an intentional lack of interest in athletes and a complete lack of communication with them. This strategy was based on the coaching principle that athletes would adapt to the situation. Indifference was mainly exhibited when an athlete was injured or had lost a competition:

Sometimes when they didn't do what they had to to win, when they have been beaten, I say nothing. I do this intentionally. I force myself to leave them in their mess. In fact, when the system doesn't work, when you define a tactic in advance and they are completely tumed around, in bad times like these, I leave. It is shocking. I wait until they corne back to have a discussion. I'm not going to take the first step. The principle works. Afterwards, if you have to wait five minutes, three days, a week, a month, it's all the same. In any case, the principle works. $(\mathrm{Cl})$

Such indifference and expectations about atllletes' perpetual effort are linked to the judo tradition, as expressed by the following coach:

The athletes that are successful know the best ways around the system, in a game that is a little bizarre. They know the never-ending effort required (exceeding this effort level), the training atmosphere, the necessary collective eff0li with rules based on a very old tradition, and the self-sacrifice. You shut your mouth and go through the days. At the same time, I ask myself if you can succeed any other way. $(\mathrm{Cl})$ 
Entering Into Direct Conflict. Conflict strategies included exacerbating the two preceding ones. They were characterized by threats regarding selection for important competitions, and a lack of interest and communication during training sessions. The underlying assumption was that athletes would give up and quit or adapt and win. Conflict arose when coaches perceived athletes' lack of engagement, results, or conformity to the unspoken rules of the system. This kind of strategy was addressed by a coach:

There I provoked conflict. You need to get it over with, start from scratch. It lasted for two weeks while she thought about it. I was sure she was going to corne back even more determined than before. (C3)

These strategies were also legitimized by the coaches' persona! experiences as elite athletes in the same system. The following quotation illustrates the perceived positive consequences of conflicting coach-athlete relationships on athletes' determination:

In the system where I lived, in certain situations I perceived my coach or some of my coaches as veritable objects to overcome. I gave myself the resources to train constantly with determination, without losing step. Globally, there is a type of challenge in talking to yourself. . . . You have established your objective and you are going to take it; that is your identity. $(\mathrm{Cl})$

Developing Specific Team Cohesion. Developing a specific team cohesion through challenging situations emerged as another coach's strategy. This was evident in the organization of precompetition training camps based on dangerous physical activities. Facing the same difficulties was supposed to build a team spirit. This sense of cohesion was intended to intimidate adversaries and, more generally, to perpetuate the French tradition of excellence in judo. The following quotation illustrates this elernent:

When the team cornes in, you feel the attention. One fears the French....You have to be proud to represent French judo, which has a history. Image is very important. (C2)

Coaches also viewed these strategies as a form of mental preparation. The effectiveness of challenging situations was seen in the development of a competitive spirit ("the will to win") and the skills for precompetitive stress management, as stated by this coach:

I require them to do certain things at many training camps, two times a year, more or less. I do this intentionally. During these camps, you do other things, not judo. Sorne things are a challenge, like go-carts, canyoning, rock climbing. You start and when you have to jump 10 meters, you do it in a positive manner. You can't hold back any longer; that is a source of conflict. But when you corne back another time, you've done it. I don't have any other methods for them to acquire this, for them to get beyond the fear, to concentrate on the event, to empty it out. (C2)

Exhibiting Favoritism. Coaches' preferentiaJ treatment for athletes selected for the most important competitions was manifest in specific coaches' behaviors 
toward athletes they supported, increased number of instructions and feedback during training sessions, and increased tolerance toward athletes' autonomy. This quotation illustrates the first element:

Clearly, at the beginning there is some type of potential, and we scout them out on the basis of complex factors. Of course, you just work more with the ones that are potential winners, I mean the one in whom you believe. But depending on the coach, we do not pick up the same one. Every one of us bets on his athlete. For example, they always thought that there was nothing to get from A2. But I never gave up on her, because when you know her, if she wants to fight to the end, she's gonna break a record. For the past three Olympics she's been at the top of her weight category. (p. C3)

In conclusion, coaches' conceptions based on the historical effectiveness of the French judo system and their perceptions of athletes' characteristics are the main underlying factors of the coaches' interaction strategies. The prevailing interaction strategies could be based on the long-standing culture of judo, which includes political issues within the French Judo Federation, and the specific value of respect. Perceived reasons for effectiveness of the previously described strategies are related to positive consequences of specific forms of mental preparation, which included pushing athletes into a corner, keeping only those who are most resistant to this mental testing, and developing a winning spirit. Coaches' empirical knowledge as coach or athlete in the same productive system was identified as a second reason.

\section{Athletes' Interaction Strategies}

Table 2 reports categories and properties that emerged from athletes' interview transcripts. Autonomy was the dominant interaction style expressed by athletes. This sense of independence was seen as a means to satisfy their personalneeds and alleviate pressures of obligation to the sport. Pive strategies within the autonomous interaction style emerged: showing diplomacy, achieving exceptional performance, soliciting coaches directly, diversifying information sources, and bypassing conventional rules. These strategies were implemented by athletes to best internet with their coaches.

Showing Diplomacy. Diplomacy was defined as making concessions to authority figures, especially in training settings. This strategy was expressed in accepting inequitable attitudes and completing nonadapted training tasks. At times, this included covertly redefining these tasks. Athletes adhered to these strategies throughout their careers. Diplomatie strategies were used frequently to deal with team selection for important competitions and, more generally, to adapt to the French judo system and rules. Diplomacy was deemed an effective strategy because it permitted athletes to avoid conflict that could negatively affect their wellbeing and also allowed each a sense of autonomy while maintaining the teacherstudent hierarchy within the spmt. The following is a relevant excerpt from an athlete's interview:

Anyway, they've got the power, you've got to adapt, to comply with the coach, in the end to be diplomatie. Sometimes, you're sick of it, it's hard, but you let them talk, and you do your stuff on your side. (Al) 


\begin{tabular}{lll}
$\begin{array}{l}\text { Athletes' interaction } \\
\text { strategies }\end{array}$ & $\begin{array}{l}\text { Underlying interaction } \\
\text { factors }\end{array}$ & $\begin{array}{l}\text { Perceived reasons for } \\
\text { effective interactions }\end{array}$ \\
\hline
\end{tabular}

Showing diplomacy: acceptance of inequitable attitudes and completion of nonadapted training tasks

Achieving exceptional performance: regular presence in training and achievement of best results in competition

Soliciting the head coach directly: initiation of communication with the head coach

Diversifying sources of information: selecting appropriate information among the coaches' competencies

Bypassing conventional rules: seeking and utilizing other assistants
French Judo system: rules of the selection process and athletes' obligation to adapt or quit

\begin{abstract}
Judo culture: historical productivity of the French system, coaches' selection rules, and subjective nature of the criteria
\end{abstract}

Athletes' self-determination: athletes' need for feedback after training or competing

Athletes' self-determination: athletes' perceptions of their needs

Athletes' self-determination: athletes' maturity and lucidity toward the system
Sense of autonomy: avoidance of conflicts and maintenance of the teacherstudent hierarchy

Positive consequences of self-determination: on results and well-being

Positive consequences of self-determination: on results and well-being

Positive consequences of self-determination: on results and well-being

Achieving Exceptional Perfonnance. This strategy involved being regularly present in training sessions and striving for the best results at competitions. This mindset was demonstrated during the team selection process when athletes were faced with the subjective nature of coaches' criteria. This strategy was linked to athletes' maturity and lucidity toward the judo system and to self-determination. One athlete commented:

My strategy is to be the best. This way, there is no photo finish; they can't say anything about it. (Al)

Soliciting Coaches Directly. Direct solicitation was defined as athletes' initiating communication with their coaches. These verbal exchanges ook place after a Joss, during training, and following difficulties encountered by the group or sport organization. These strategies were motivated by the athletes' 
self-determination and need for feedback. They were also initiated by the lack of spontaneous communication from coaches with unsuccessful athletes. The following quotation demonstrates this strategy:

I had finished fifth, but I should have been at least third; I discussed it with my coach. This allowed us to know each other better, to understand and to move forward. (A5)

Diversifying Information Sources. Diverse information sources available to athletes include the three official coaches' broad-based knowledge and estimated competence. Selection is dictated by each athlete's individual needs. This strategy was labeled "shopping for a coach" and was demonstrated in the selection of appropriate information among different coaches' competencies, as explained in the following quotation:

The three coaches are very different with respect to their level of technical knowledge and their personalities. 1 think it is like having a trump card, because 1 try to take the best they each have to offer. (A3)

Bypassing Conventional Rules. Bypassing conventionality took the form of seeking coaches or assistants outside the regular training framework. Sorne of these strategies were considered clandestine. These included using a persona trainer, male training partners, or sport psychologists. An example of such a strategy would be listening to a nonofficial coach in the stands during competition while the official national coach is giving advice on the mat. Another nonconventional method is revealed in the following quotation:

I went to see another trainer, a friend of mine who works in a gym/weight room. I asked him, "What can I do for weight training?" (A2)

These strategies were clearly linked to athletes' self-determination and perception of their needs, as expressed by this athlete:

I'm at a period in my life as an athlete where 1don't want things imposed on me, I want to do things that please me, and be able to choose. I know what 1 want to do, and the coach is not as important to me. (A3)

Finally, the French judo system constraints, which included coaches' conceptions and their rules of the selection process, as well as athletes' obligations to adapt or quit, were the major underlying factors behind athletes' interaction strategies. Their determination to succeed and perception of their needs also appeared as important factors. Persona! characteristics involved the athlete's age since younger athletes were more accepting of the system:

If you are Olympie champion, you can allow yourself to say, "I worked like this because I had to get here," but at the beginning, you do what everyone else does. You are obligated, and you bend to the discipline. (Al)

Ingeneral, athletes could not question the coaches' authority since this was a significant component of judo in France. Athletes' subsequent autonomous displays were perceived as effective because they were a way of exerting selfdetermination while maintaining their positions on the national team. 


\section{Compatibility and Effectiveness of Coaches' and Athletes' Strategies}

Analysis of coaches' and athletes' interview transcripts revealed different interaction strategies and underlying factors. However, some perceived reasons of effectiveness related to the tradition and productivity of the French system were shared. Several training and competition situations were elicited by coaches and athletes. They were motivated by a common goal-to dominate the world-and by two subgoals-to be successful in the selection process for important competitions and optimize the pe lformance process. Descriptive and explanatory analyses of coaches' and athletes' respective strategies showed some particular compatibility and effectiveness of their interactions. Figure 1 illustrates a schema of this adjustment with respect to their shared goals.

An important element of this effectiveness seemed to be due to athletes' and coaches' adaptation to their respective power in the system. Athletes adjusted well to the subjective selection process, and coaches made tacit concessions when faced with autonomous objectives of successful athletes. However, regarding the decision making of the selection process, coaches resorted to an authoritative mode. They encouraged specific interpersonal rivalry, displayed indifference, provoked athletes verbally, and instigated conflict situations so that they could retain only the most resilient athletes. Consequently, athletes resorted to strategies grounded in diplomacy while striving for excellent results. Coaches then showed preferential treatment toward selected athletes and changed their attitudes toward those who were frequent medalists. This behavior was demonstrated by less disagreeable interactions and increased tolerance toward athletes' autonomy. Coaches also tried to reinforce successful athletes' cohesion and mental skills by confronting them with challenging situations. At the same time, athletes who deemed it necessary

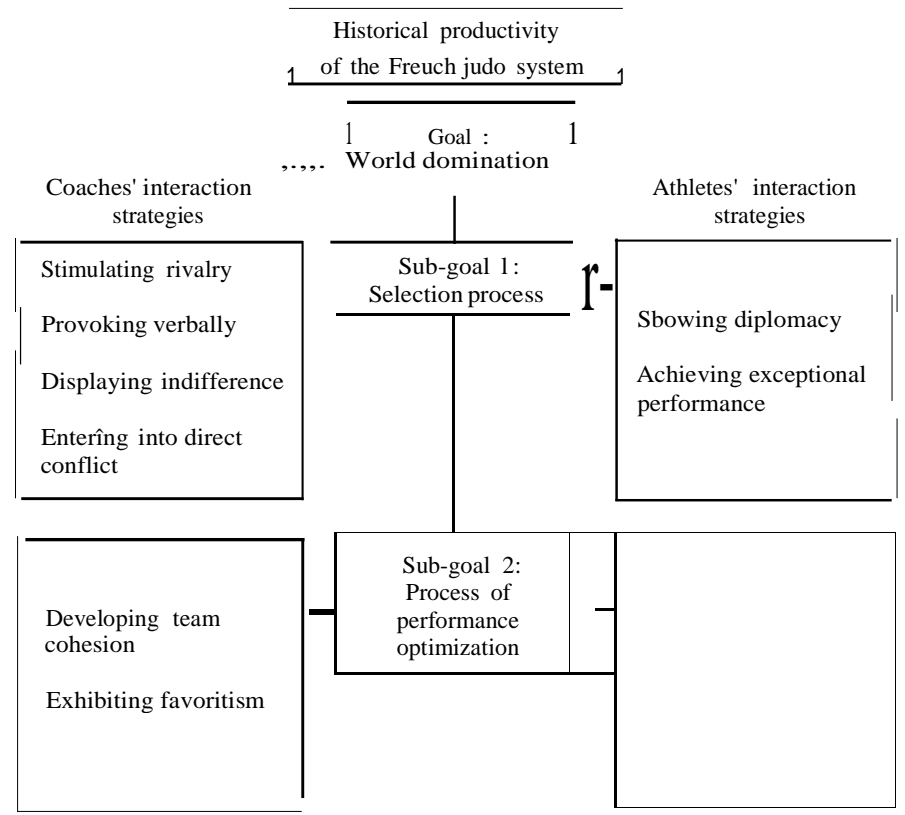

Figure 1-Compatibility and effectiveness of coaches' and athletes' strategies regarding common goals and subgoals. 
for their optimal performance resorted to direct solicitation, pursued diverse information sources (shopping for a coach), and bypassed authority. The adequacy of these reciprocal strategies favor the self-regulation of the French judo system.

\section{Discussion}

The interaction style used by expert judo coaches can be compared to preexisting sport leadership styles, in particular, the autocratie behaviors outlined by Chelladurai and Saleh (1980) and Chelladurai (1993). Judo coaches' authoritative mode included six interaction strategies: stimulating rivalry, provoking verbally, displaying indifference, entering into direct conflict, developing team cohesion, and exhibiting favoritism.

These results revealed certain elements not consistently seen in leadership literature, such as the positive consequences of lacking social support and using negative feedback. Such results differ from those in the coaching literature regarding expert coaches in gymnastics (Côté, Salmela, \& Russell, 1995a; Côté \& Salmela, 1996), rowing (Côté \& Dowd, 1996), and sailing (Saury \& Durand, 1995) as well as general coaching behaviors (e.g., Ten-y \& Howe, 1984; Salmela, 1996). The above studies revealed coach-athlete relationships as comfortable collective works, based on collaboration, social support and fun, with a humanistic mission surpassing sport performance.

Moreover, some of the perceived reasons for effective interactions between coaches and athletes differ from conventional findings in the sport psychology literature. Judo coaches encouraged rivalry, which can be partly attributed to the wan-ior-like motivational climate (Ames, 1992) that has surrounded the sport for many years. Kavussanu and Roberts (1996) suggested that this type of learning atmosphere negatively affected athletes' enjoyment levels and lowered their feelings of competence, especially among female tennis players. While similar negative consequences may have been generated within the French judo system, specifically with the less mentally strong athletes, such tough coaching styles are perceived as necessary for athletes' commitment and development of a winning spirit. Basically, the fonns of mental preparation that French judo coaches emphasized are not supported by conventional manuals in sport psychology (Williams, 1997), nor were they represented in the Kavussanu and Roberts (1996) sample.

However, traditional management models illustrate similar leadership styles in which system productivity requires autocracy and centralization (Lévy-Leboyer, 1974). Within industrial/organizational psychology, pailicipative decision making has been suggested as a panacea to reestablishing a positive rapport and equilibrium and as a source of reducing individual performances because of lacking control (Leplat, 1994). By focusing on each pallner's roles and fonctions in a specific context rather than solely on the coach's leadership style, our study outlines a horizontal approach to coach-athlete relationships, with implications for the importance of more traditional management models within particulai-situational constraints, where winning is essential.

Furthermore, underlying factors of interactions that emerged in the present study help to fine-tune the dimensions of Côté et al.'s (1995) coaching model within the French judo context. Qualitative analyses revealed that training and competition settings depend upon a central goal (i.e., perpetuating the French judo tradition of excellence) and two subgoals (i.e., being successful in the selection process and optimizing the performance process). Coaches' and athletes' personal 
characteristics have been redefined within the French judo system. For political and cultural reasons and because of the personal stakes, coaches have adopted autocratie methods. Such coaching styles have been previously evaluated as effective and are seen as needing perpetuation. Coaches who have democratic intentions or who want to change the system are not accepted. Moreover, because the number of young athletes who want to succeed is so large, the French judo system can be very selective and retains only the most motivated and resilient athletes. Consequently, coaches and athletes who stay in the system understand and accept its restrictive rules. This system could be compared to the coaching styles identified in some professional sports, in which business and finances are predominant. For example, coaches interviewed by Salmela (1996) reported that the two highestpaid coaches in ice hockey are very impersonal and demanding and play mind games with their players, as was expected by management.

However, the unconventional athletes' strategies that emerged in the present study suggest that their coaches' authoritative style was not appreciated, although it could be evaluated as effective. These findings can be associated with those of Chelladurai (1984) and Fonséca and Rocha (1995), who showed that athletes preferred democratic leadership. Judo athletes are constantly caught in a contradictory situation: They adhere to a system because it is effective and produces results, but they are opposed to the same system because it is incompatible with their needs for self-determination (Deci \& Ryan, 1985). These athletes' strategies are similar to those evoked by De Terssac (1991) in terms of the autonomous organization of executives in the workforce. For example, executives contest corporate regulations and elaborate on unwritten rules, behaviors that are similar to those of athletes in the present study. The compatibility of the workers' strategies in De Terssac's study (1991) favors a particular form of collective work, which Lacoste (1991) entitled "tacit cooperation."This form of cooperation consists of the compatibility of different strategies or resources. It does not assume that representations of situations are shared and that strategies are collectively elaborated or negotiated. This form of collective work is based on power balance and strategic actions regarding common goals or interests. Such a theoretical framework is useful in interpreting coaches' and athletes' interactions in the present study and suggests why these interactions are effective.

Finally, we discovered a system that, while most sport psychologists would consider it unhealthy and require change, has been remarkably successful. Conventional literature holds that such tough coaching styles could lead to negative outcomes for athletes' persona !development and, consequently, performance, specifically with the youngest athletes. The present study suggests that highly successful athletes have coping strategies and do not seem to be affected by coaches' often unpleasant decisions and behaviors. These athletes are or have become mentally strong and mature enough to override these attitudes and function well within the system. To what degree the coaching styles might be responsible for building these mental skills has yet to be determined.

In any case, the French judo system suggests that a form of autonomy can emerge in a restrictive system, perhaps even from it, whereas other current findings show that democratic coaching strategies are preferable. This study could help coaches and athletes who internet within a system that is highly affected by political, cultural, and business factors to analyze the compatibility and effectiveness of their respective strategies. 


\section{References}

Ames, C. (1992). Achievement goals, motivational climate, and motivational processes. In G.C. Roberts (Ed.), Motivation in sp011and exercise (pp. 161-176). Champaign, IL: Human Kinetics.

Chelladurai, P.(1984). Discrepancy between preferences and perceptions of leadership behavior and satisfaction of athletes in varying sports. Journal of Sport Psychology, 6, 27-41.

Chelladuraî, P. (1993). Leadership. In R.N. Singer, M. Murphey, \& L.K. Tennant (Eds), Handbook of research on sport psychology (pp. 647-671). New York: Macmillan.

Chelladurai, P., \& Carron, A. (1978). Leadership. Ottawa, ON: Sociology of Sport Monograph Series, Canadian Association for Health, Physical Education and Recreation.

Chelladurai, P., \& Saleh, S. (1980). Dimensions of a leader behavior in sports: Development of a leadership scale. Journal of Sp011 Psychology, 2, 34-45.

Côté, J., \& Dowd, J. (1996). Coaches expertise in rowing: A qualitative investigation of Canadian athletes and coaches. Journal of Sport and Exercise Psychology Abstracts, 18 (suppl.): S103.

Côté, J., \& Salmela, J.H. (1996). The organizational tasks of high-performance gymnastic coaches. The Sport Psychologist, 10, 247-260.

Côté, J., Salmela, J.H., \& Russell, S. (1995a). The knowledge of high-performance gymnastic coaches: Competition and training considerations. The Sport Psychologist, 9, 76-95.

Côté, J., Salmela, J.H., \& Russell, S. (1995b). The knowledge of high-performance gymnastic coaches: Methodological framework. The Sport Psychologist, 9, 65-75.

Côté, J., Salmela, J.H., Trudel, P., Baria, A., \& Russell, S. (1995). The coaching expert model: A grounded assessment of expert gymnastic coaches' knowledge. Journal of Sport and Exercise Psychology, 17, 1-17.

Deci, E.L., \& Ryan, R.M. (1985). Intrinsic motivation and self detennination in human behavior. New York: Plenum Press.

De Terssac, G. (1991). Autonomie dans le travail [Autonomy in the workplace]. Paris: PUF.

Fonséca, H.M., \& Rocha, H. (1995). Perception par les coaches du style de leadership préféré des athlètes [Coaches' perception of athletes' preferred leadership style]. Sport, $151,40-45$.

Glaser, B.G., \& Strauss, AL. (1967). The discovery of grounded theory: Strategies for qualitative research. Chicago: Adldine.

Hanson, T., \& Newburg, D. (1992). Naturalistic inquiry as a paradigm for doing applied performance enhancement research. Contemporary Thought on Performance Enhancement, 1(1), 26-40.

Home, T., \& Carron, A.V. (1985). Compatibility in coach-athlete relationships. Journal of Sport Psychology, 7, 137-149.

Kavussanu, M., \& Roberts, G.C. (1996). Motivation in physieal activity contexts: The relationships of perceived motivational climate to intrinsic motivation and self-efficacy. Journal of Sport and Exercise Psychology, 18, 264-280.

Lacoste, M. (1991). Les communications de travail comme interactions [Work communications as interactions]. In R. Amalberti, M. de Montmollin, \& J. Theurean (Eds.), Modèles en analyse du travail (pp. 191-229). Lièges, France: Mardaga.

Leplat, J. (1994). Collective activity in work: Sorne ways of research. Le Travail Humain, 57(3), 201-202.

Lévy-Leboyer, C. (1974). Psychologie des organisations [Psychology of organizations]. Paris: PUF.

Orlick, T. (1986). Psyching for sport. Champaign, IL: Human Kinetics. 
Salmela, J.H. (Ed.). (1996). Greatjob coach. Ottawa, ON: Potentium.

Saury, J., \& Durand, M. (1995). Etude des connaissances pratiques des entraîneurs experts en voile. De l'analyse des relations entraîneurs-athlètes à une approche de la situation d'entraînement comme un travail collectif [Practical knowledge of expert sailing coaches. From the analysis of the coach-athlete relation ship to an approach of the training situation as a collective work]. Sport, 151,25-39.

Scanlan, T.K. (1993, October). Testing... Testing... Where is sport psychology? Paper presented at the annual meeting of the Association for the Advancement of Applied Sport Psychology, Montréal, PQ.

Spradley, J. (1979). The ethnographie interview. New York: Holt, Rinehart.\& Winston.

Strauss, A., \& Corbin, J. (1990). Basics of qualitative research: Grounded theory procedures and techniques. Beverly Hills, CA: Sage.

Terry, P.C., \& Howe, B.L. (1984). Coaching preference of athletes. Canadian Jaumal of Applied Sport Science, 9, 188-193.

Williams, J.M. (Ed.). (1997). Applied sport psychology: Persona! growth to peak peiformance. Mountain View. CA: Mayfield.

\section{Acknowledgments}

This study was supported by a grant from the French Ministry of Youth and Sport. We thank Philippe Fleurance, Jacques Saury, Marc Durand, John H. Salmela, and Whitney Sedgwick for their helpful comments on earlier drafts of the manuscript. 